\title{
Grain filling and shoot growth of 2-row and 6-row winter barley varieties
}

\author{
J Le Gouis \\ INRA, laboratoire de Génétique et d'Amélioration des plantes, F-80200, Estrées-Mons, France
}

(Received 30 November 1992; accepted 14 April 1993)

\begin{abstract}
Summary - The growth of the grain and shoots of 36 barley (Hordeum vulgare L) genotypes (18 2-row and 18 6row) has been studied in northern France. A linear model showed that there was genotypic variation in both rate and duration of grain filling (GF) and shoot growth (SG). GF rate per grain was closely associated with kernel weight $(r=$ $0.584^{\star \star}$ and $r=0.824^{\star *}$ for the 2-row and the 6-row varieties respectively). A strong negative phenotypic correlation was, however, found between GF rate per grain and duration for the 2-row genotypes $\left(r=-0.712^{\star \star}\right)$. The SG and GF rates for the majority of genotypes were similar. On average, the GF rate of 6-row was, however, higher than their SG rate $\left(2.11\right.$ against $\left.1.93 \mathrm{~g}^{\bullet} \mathrm{m}^{-2}\right)$. The translocation of assimilates previously stored in vegetative parts may then explain the higher yield of 6-row genotypes. On average, SG stopped before GF and the means for the 2- and the 6-row varieties were not significantly different.
\end{abstract}

Hordeum vulgare L / 2-row barley / 6-row barley / dry matter accumulation / genotypic variability

Résumé - Remplissage du grain et croissance de la tige chez des variétés d'orge d'hiver à 2 et à 6 rangs. $L a$ croissance du grain et de la matière sèche aérienne végétative de génotypes d'orge (Hordeum vulgare L), 18 à 2 rangs et 18 à 6 rangs, a été étudiée dans le nord de la France. Un modèle linéaire a été utilisé pour estimer les vitesses et les durées de remplissage du grain (GF) et de croissance de la matière sèche aérienne végétative (SG). Des différences génotypiques ont été mises en évidence pour les vitesses et les durées de SG et GF. La vitesse de GF par grain est fortement corrélée au poids d'un grain $\left(r=0,584^{\star \star}\right.$ et $r=0,824^{* \star}$ pour les 2 rangs et les 6 rangs respectivement). Une forte corrélation phénotypique négative a été cependant trouvée entre la vitesse et la durée de GF pour les 2 rangs $\left(r=-0,712^{\star *}\right)$. La comparaison des vitesses de GF et de $S G$ montre que, pour la majorité des génotypes, ces 2 vitesses sont similaires. En moyenne, la vitesse de GF des 6 rangs est cependant supérieure à celle de leur SG $\left(2,11\right.$ contre $\left.1,93 \mathrm{~g} \mathrm{~m}^{-2}\right)$. La translocation d'assimilats stockés préalablement dans les tiges peut expliquer le rendement supérieur des 6 rangs. En moyenne, la SG stoppe avant la GF, et les moyennes pour les 2 rangs et les 6 rangs ne sont pas significativement différentes.

Hordeum vulgare $L$ / orge à 2 rangs / orge à 6 rangs / accumulation de matière sèche / variabilité génotypique

\section{INTRODUCTION}

Kernel weight is an important component of yield in winter barley (Hordeum vulgare $\mathrm{L}$ ). It is also the last component to be determined. Final grain weight is a function of rate and duration of grain filling (GF). Genotypic variation for these 2 parameters has been reported for spring wheat (Triticum aestivum $\mathrm{L}$ ) by Nass and Reiser (1975) and Bruckner and Frohberg (1987), winter wheat by Van Sanford (1985) and Triboi (1990), spring oats (Avena sativa L) by Wych et al (1982) and spring barley by Riggs and Gothard (1976), Scott $e$ t al, 1983) and Ho and Jui (1989).

Ho and Jui (1989) compared GF rates and durations of 2- and 6-row barley varieties, working only on the central rows of the 6-row spike. They found that the 2-rows had a shorter GF duration than the 6-rows. Their GF rate was higher than or equivalent to that of the 6-rows. 
Most authors reported that the GF rate explains the differences between genotypes for final kernel weight better than does its duration (Nass and Reiser, 1975; Jones et al, 1979; Van Sanford, 1985; Bruckner and Frohberg, 1987; Campbell et al, 1990; Triboi, 1990). Daynard et al (1971) working on corn (Zea mays L) found, however, that GF duration was the most important factor and some other authors showed that both parameters may have an influence (Sofield et al, 1977; Gebeyehou et al, 1982). High temperature has been shown to have a strong negative action on GF duration (Sofield et al, 1977; Spiertz, 1977).

Gallagher et al (1975) distinguished 3 phases during the GF period. During the first phase, ear growth rate is inferior to crop growth rate. Then ear growth rate increases and becomes superior to crop growth rate. During the third phase, crop growth stops but ear growth continues for a while. Assimilates produced during the first phase are stored in plant parts other than the grain. On the contrary, during the other phases, assimilates are translocated to the grain. It seems that no work has been carried out to assess the varietal differences between shoot growth (SG) and GF rates in cereals and to estimate the duration of these different phases.

Winter barley, both 2- and 6-row, is the main type of barley in France and this crop has not yet been studied thoroughly as far as grain filling is concerned. The objectives of this study were therefore to: 1) evaluate genotypic variation for rates of SG and GF in a set of winter barley genotypes; 2) compare 2- and 6-row genotypes for Gf and SG parameters; 3) investigate the relationship between GF parameters and kernel weight; 4) examine the association between SG and $\mathrm{GF}$ rates and durations.

\section{MATERIALS AND METHODS}

Thirty-six barley cultivars were grown in the field at the plant breeding station of Estrées-Mons (the Somme, northern France) in 1989. Thirty of the cultivars were winter barley registered between 1963 and 1988 which represented a large part of the French seed production area. The other genotypes were: 1) 2 registered spring barley varieties (Cytris and Triumph); 2) 2 experimental lines bred at the INRA plant breeding stations of Clermont-Ferrand (CF 84-234) and Montpellier (LM 911), the last one being a hulless barley; and 3) 2 North African cultivars (Acsad 176 and Tichedrett). Eighteen genotypes were 2-row and 18 were 6row.
The cultivars for the experiment were sown on October 6 on a deep silt loam soil. The experimental design was a lattice square with 4 replications. At the beginning of stem elongation, the average density was 260 plants $\mathrm{m}^{-2}$. Nitrogen fertilizer was applied according to a predictive balance sheet method based on soil test results for a target yield of 9 toha $^{-1}\left(170 \mathrm{~kg} \mathrm{~N} \mathrm{ha}^{-1}\right)$. Pesticide treatments were applied in order to completely control parasites. Two growth regulators were sprayed to limit the risk of lodging $\left(670 \mathrm{~g}^{\bullet} \mathrm{ha}^{-1}\right.$ mepi-

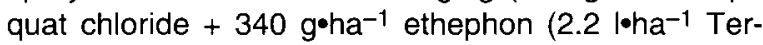
pal) and $480 \mathrm{~g}^{\bullet} \mathrm{ha}^{-1}$ ethephon ( 1 l ha ${ }^{-1}$ Ethéverse).

Each plot consisted of $65-\mathrm{m}$ rows sown $0.2 \mathrm{~m}$ apart. A single treatment was represented by 5 adjacent plots. One plot was harvested at maturity and 1 at anthesis. Results of these 2 sampling dates have been presented elsewhere (Le Gouis, 1992). Sampling began 2 to $4 \mathrm{~d}$ after flowering (50\% of the ears with visible stamens). A total of 50 shoots were cut at ground level twice per wk in the 4 middle rows of the plots with 4 replications. Sampling terminated when no green tissue remained, this being considered as a good indicator of physiological maturity (Copeland and Crookston, 1985). A total of 13-16 harvests were completed for each cultivar. Shoots were dried at $90^{\circ} \mathrm{C}$ for $48 \mathrm{~h}$ and then weighed. Grains were taken from at least 10 ears, weighed and counted.

At each sampling date, shoot and grain dry matter (DM) were divided by the number of grains. They were plotted as a function of accumulated growing-degree days (GDD) from anthesis. GDD were calculated as [(daily min temp - daily max temp) / 2 - base temp], where base temperature was $0^{\circ} \mathrm{C}$ (Triboi et al, 1985).

GF rates were determined from linear regressions during the linear phase of DM accumulation (Riggs and Gothard, 1976). Coefficients of determination were all $>0.96$. Final grain weights were estimated by calculating the mean of the last 3 sampling dates. GF durations were determined by dividing final grain weights by GF rates. The ends of GF were calculated as the dates at which the grain would have reached its maximal weight provided that the GF rate estimated during the linear accumulation period had been maintained constant.

The same calculations were carried out for SG per grain. SG rates were calculated from linear regressions during the period of rapid accumulation of dry matter (fig 1). Coefficients of determination ranged from 0.82 to 0.97 , most of them being $>0.90$, indicating that a linear model fitted quite well to this period of growth. Maximal shoot weights were determined by calculating the mean of the 3 highest shoot weights, since a decrease in shoot weight was seen in some cultivars near maturity. The ends of SG were calculated as the dates at which the shoot would have reached its maximal weight provided that the $S G$ rate estimated by linear regression had been constant throughout. SG durations were estimated from anthesis. Since root growth is very limited after anthesis (Gallagher et al, 1975), the observation of shoot growth is a good estimation of whole plant growth. 
The numbers of grains per ear were calculated as the means over all sampling dates. The numbers of ears $\bullet \mathrm{m}^{-2}$ determined at maturity on the adjacent plots were used to estimate the numbers of grains ${ }^{-2} \mathrm{~m}^{-2}$, grain and shoot $\mathrm{DM} \bullet \mathrm{m}^{-2}$, GF and $\mathrm{SG}$ rates $\mathrm{m}^{-2}$.

Within the 2- and 6-rows, an analysis of variance as described by Dagnélie (1970) was carried out to test whether significant differences for GF and $S G$ rates could be found. The means of the 2- and 6-rows were compared using a $t$-test. Confidence intervals for the rates and the durations were calculated as explained by Dagnélie (1970). The SG and GF rates or the SG and GF durations for any cultivar were determined as significantly different if their confidence intervals did not overlap.

\section{RESULTS AND DISCUSSION}

\section{Comparison of growing conditions}

Before comparing growth parameters between cultivars, it is important to verify that the growing conditions were equivalent and that no severe stress occurred.

Soil water content measurements were carried out weekly from anthesis onwards (data not communicated). These showed that the soil water content between 0 and $1.20 \mathrm{~m}$ depth remained greater than the value corresponding to the permanent wilting percentage estimated for this type of soil up to maturity. Water was therefore not a limiting factor.

Diseases were adequately controlled except in Acsad 17, a North African cultivar, which suffered from a severe attack of leaf rust (Puccinia hordei OTTH). Lodging occurred on some cultivars, mainly 6-rows, 2 wk after the average date of anthesis (May 14). It was, however, possible to sample in non-lodged parts of the plot for all varieties except Smash and Tichedrett. The results of these 2 varieties may have been affected accordingly.

GF rate is faster at high temperatures (Sofield et al, 1977). Mean daily air temperatures ranged from $13.2^{\circ} \mathrm{C}$ to $13.7^{\circ} \mathrm{C}$ during the GF period and from $13.1^{\circ} \mathrm{C}$ to $14.3^{\circ} \mathrm{C}$ during the SG period. Excluding Acsad 176 which has a very early flowering date, the latter range is only $13.1-13.7^{\circ} \mathrm{C}$. The 2- and the 6-row varieties experienced the same mean daily air temperatures $\left(13.4^{\circ} \mathrm{C}\right.$ and $13.5^{\circ} \mathrm{C}$ respectively). Bruckner and Frohberg (1987) also reported a limited range of mean air temperatures during GF for 20 genotypes of

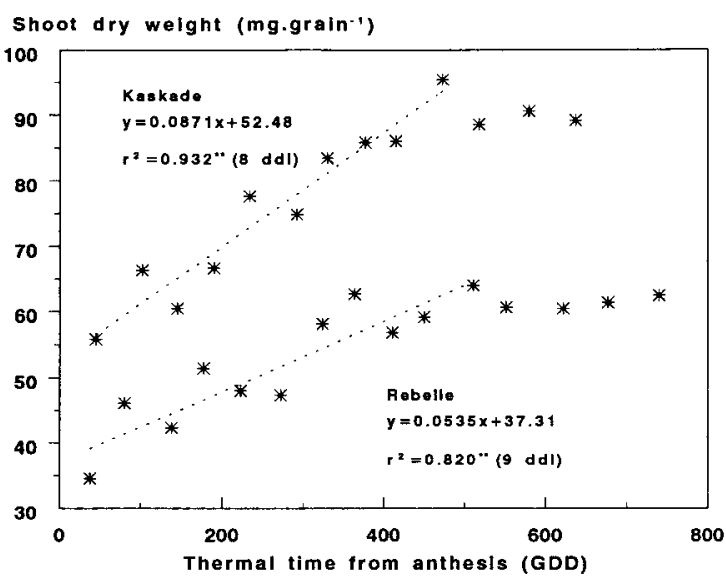

Fig 1. Shoot weight plotted as a function of thermal time (growing-degree days) for the winter barley cultivars Kaskade (2-row) and Rebelle (6-row).

spring wheat $\left(22.5\right.$ to $\left.23.2^{\circ} \mathrm{C}\right)$. They showed, however, that GF duration was negatively correlated with temperature. We found no correlation under our conditions ( $r=0.014^{\text {ns }}$ with $34 \mathrm{df}$ ). The mean daily air temperature was far lower in our experiment, and this may explain that difference.

Except for the 2 North African genotypes and the Smash variety, we can conclude that the growing conditions were similar for all genotypes.

\section{Variability of GF and SG rates and durations}

A significant genotypic variation existed for GF and $S G$ rates per $m^{2}$ and per grain. GF rates ranged from 60.8 to $102.0 \mu \mathrm{g} \cdot \mathrm{grain}^{-1} \cdot \mathrm{GDD}^{-1}$ and from 1.56 to $2.53 \mathrm{~g} \cdot \mathrm{m}^{-2} \cdot \mathrm{GDD}^{-1}$ (table I). SG rate was between 39.1 and $141.1 \mu$ g $^{\circ}$ grain $^{-1}$. $\mathrm{GDD}^{-1}$ or between 0.95 and $2.86 \mathrm{~g}^{\circ} \mathrm{m}^{-2} \cdot \mathrm{GDD}^{-1}$ (table I).

The 2-row genotypes had a higher average GF rate per grain than the 6-rows (table II). Mean GF durations were very similar for both types of barley. These results are slightly different from those of Ho and Jui (1989) who studied 15 genotypes of spring barley. They found that the mean GF rate of the 2-rows was higher than or equivalent to the GF rate of the 6-rows; however, the GF duration of the former was shorter. These authors, however, considered only the kernels from the central rows of 6-row varieties. Scott et al (1983) showed that in 6-rows, GF rate 
and duration of lateral grains were lower than those of the central grains. In our experiments, we took into account the lateral grains, and this may explain the difference between our results and those of Ho and Jui (1989) together with the fact that they studied spring barley.
Comparison of 2- and 6-rows showed that their rates of SG on a per area unit basis $\left(\mathrm{g} \cdot \mathrm{m}^{-2}\right)$ were similar, but that the 6-row rate of GF was higher. This is due to the greater number of grains per $\mathrm{m}^{2}$ in the 6-row genotypes (table II). As GF durations were equivalent for the 2- and 6-rows, the

Table I. Genotypic values of the 2-row and 6-row barley cultivars for grain filling (GF) and shoot growth (SG) parameters.

\begin{tabular}{|c|c|c|c|c|c|c|c|c|c|}
\hline \multirow{2}{*}{$\begin{array}{l}\text { Genotype } \\
\text { (code) }\end{array}$} & \multicolumn{6}{|c|}{ GF parameters } & \multicolumn{3}{|c|}{ SG parameters } \\
\hline & $\begin{array}{l}\text { End } \\
(G D D)^{a}\end{array}$ & $\begin{array}{l}\text { Duration } \\
\text { (GDD) }\end{array}$ & $\begin{array}{l}\text { Rate } \\
\text { (g•grain } \\
\left.\cdot G D D^{-1}\right)\end{array}$ & $\begin{array}{l}\text { Grain } \\
(m g)\end{array}$ & $\begin{array}{l}\text { Rate } \\
\left(g^{\bullet} m^{-1}\right. \\
\left.\cdot G D D^{-1}\right)\end{array}$ & $\begin{array}{l}\text { Grain } \\
\left(g \cdot m^{-2}\right)\end{array}$ & $\begin{array}{l}\text { End } \\
\text { GDD }\end{array}$ & $\begin{array}{l}\text { Rate } \\
\left(g^{\bullet} m^{-2}\right. \\
\left.\cdot G D D^{-1}\right)\end{array}$ & $\begin{array}{l}\text { Shoot } \\
\left(g \bullet m^{-2}\right)\end{array}$ \\
\hline
\end{tabular}

Two-rows:

Alpha (al)

Bélivia (be)

Clerix (cl)

Cytris (cy)

Fédora (fe)

Flamenco (fl)

Igri (ig)

Kaskade (ka)

LM $911(\mathrm{~lm}) \quad 518$

Magie (mg) $\quad 551$

Marianne (mn) 500

Marylin (mr) 481

Mogador (mo) 542

Mosar (ms) $\quad 527$

Panda (pn) 550

Pastoral (pa) 547

Sonja (so) $\quad 481$

Triumph (tr)

468
458
509
410
425
507
451
452
394
508
445
456
529
494
524
522
480
506

78.6

100.3

87.8

98.8

86.5

92.3

91.5

97.3

98.7

79.4

100.5

96.2

75.2

80.3

79.4

78.7

87.0

65.2

\section{Six-rows:}

Acsad (AC)

Ager (AG)

Barberousse (BA) 485

Borwina (BO) 515

Celtic (CE) 487

CF 84-234 (CF) 471

Eldorado (EL) 485

Express (EX) 526

Gerbel (GE) $\quad 471$

Glénan (GL) $\quad 540$

Jaidor (JA) $\quad 533$

Manitou (MI) 502

Matador (MT) 520

Plaisant (PL) 497

Rebelle (RE) 520

Robur (RO) $\quad 535$

Smash (SM) 439

Tichedrett (TI) 483

444
462
468
500
466
437
479
511
436
522
451
468
499
496
498
515
405
434

76.4

60.8

33.9

$61.7 \quad 28.9$

$69.0 \quad 34.5$

$72.8 \quad 33.9$

70.0

65.8

77.3

75.2

71.8

78.8

82.0

71.2

66.7

64.0

66.4

88.3

102.0

31.5

39.5

32.8

37.5

$\begin{array}{ll}36.8 & 1.91 \\ 45.9 & 2.05 \\ 44.7 & 1.79 \\ 39.9 & 2.30 \\ 36.8 & 2.18 \\ 46.8 & 1.82 \\ 41.3 & 1.99 \\ 44.0 & 1.99 \\ 36.3 & 1.99 \\ 40.3 & 1.90 \\ 44.7 & 2.35 \\ 43.9 & 1.67 \\ 39.8 & 2.07 \\ 39.7 & 1.96 \\ 41.6 & 1.79 \\ 41.1 & 1.95 \\ 41.8 & 1.85 \\ 33.0 & 1.56\end{array}$

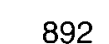

\section{8}

909

931

928

921

899

901

733

966

1047

760

1093

970

938

1016

890

790

1.89

2.12

2.29

1.81

2.02

2.27

1.84

2.14

2.00

2.18

2.53

2.27

1.83

2.07

2.18

2.19

2.24

2.15

$\begin{array}{lll}368 & 1.44 & 1777 \\ 472 & 2.14 & 2068 \\ 365 & 1.95 & 1813 \\ 415 & 1.83 & 2097 \\ 454 & 1.99 & 1929 \\ 423 & 2.24 & 2055 \\ 489 & 0.95 & 1956 \\ 450 & 1.78 & 1878 \\ 409 & 1.70 & 1822 \\ 400 & 2.62 & 1897 \\ 462 & 2.86 & 2286 \\ 309 & 2.44 & 1873 \\ 478 & 1.72 & 2178 \\ 505 & 1.51 & 2035 \\ 500 & 1.56 & 1922 \\ 485 & 1.84 & 2119 \\ 510 & 1.60 & 2039 \\ 595 & 0.97 & 1765\end{array}$

$\begin{array}{rrrr}837 & 516 & 1.96 & 1838 \\ 980 & 490 & 1.36 & 1835 \\ 1071 & 498 & 2.05 & 2109 \\ 906 & 451 & 1.84 & 1885 \\ 938 & 380 & 2.09 & 1824 \\ 994 & 414 & 2.31 & 2033 \\ 881 & 438 & 1.82 & 1890 \\ 1096 & 410 & 2.16 & 2058 \\ 874 & 476 & 1.26 & 1860 \\ 1141 & 448 & 2.51 & 2136 \\ 1138 & 578 & 2.36 & 2221 \\ 1063 & 485 & 1.95 & 2121 \\ 911 & 485 & 1.23 & 1865 \\ 1029 & 463 & 1.38 & 1967 \\ 1087 & 480 & 1.82 & 2147 \\ 1128 & 441 & 2.60 & 2041 \\ 907 & 412 & 1.93 & 1966 \\ 935 & 493 & 2.02 & 2149\end{array}$


Table II. Comparison between 2- and 6-row winter barley genotypes for grain filling (GF) and shoot growth (SG) parameters and other agronomic traits.

$\frac{\text { Two-rows }}{\text { Mean SE }} \frac{\text { Six-rows }}{\text { Mean SE }}$

\begin{tabular}{|c|c|c|c|c|}
\hline GF end (GDDa) & 509 & 6.80 & 500 & 6.29 \\
\hline GF duration (GDD) & 474 & 9.58 & 472 & 7.76 \\
\hline $\begin{array}{l}\text { GF rate } \\
\left(\mu g^{\prime} \text { grain }^{-1} \cdot G D D^{-1}\right)\end{array}$ & 87.4 & 2.41 & 73.3 & 2.39 \\
\hline Grain weight (mg) & 41.0 & 0.87 & 34.4 & 0.91 \\
\hline GF rate $\left(g \cdot \mathrm{m}^{-2} \cdot \mathrm{GDD}^{-1}\right)$ & 1.95 & 0.05 & 2.11 & 0.04 \\
\hline Grain yield $\left(\mathrm{g} \cdot \mathrm{m}^{-2}\right)$ & 918 & 21.4 & 995 & 23.7 \\
\hline SG end (GDD) & 449 & 15.6 & 464 & 10.9 \\
\hline$S G$ rate $\left(g \bullet m^{-2} \cdot G D D^{-1}\right)$ & 1.84 & 0.12 & 1.93 & 0.10 \\
\hline Shoot DM $\left(\mathrm{g} \cdot \mathrm{m}^{-2}\right)$ & 1973 & 34.3 & 1997 & 31.0 \\
\hline No of spikes $\left(\mathrm{m}^{-2}\right)$ & 901 & 22.5 & 615 & 17.6 \\
\hline No of grains per ear & 25.0 & 0.42 & 47.6 & 1.06 \\
\hline No of grains $\left(m^{-2}\right)$ & 22491 & 585 & 29212 & 978 \\
\hline Anthesis date (GDD) & 1734 & 8.5 & 1715 & 14.3 \\
\hline
\end{tabular}

a GDD: accumulated growing-degree days.

difference in GF rates per $\mathrm{m}^{2}$ accounted for the yield difference observed between the 2 types of barley (table II).

GF rate per grain was closely associated with kernel weight in both sets of 2-row and 6-row genotypes as phenotypic correlations were $r=$ $0.584^{\star \star}$ and $r=0.824^{\star \star}$ respectively. However, as shown in figure 2, some genotypes showed a particular behaviour: 3 of them displayed a low grain weight with regard to their GF rate. The experimental line LM $911(\mathrm{Im})$ is a hulless barley. Hulls are already formed at anthesis; thus their absence in the harvested kernels has no influence on GF rate, but the expected grain weight is lower. The cultivar Smash (SM) suffered from lodging. It seems that this accident only limited GF duration, since the GF rate remained quite high. The spring variety Cytris (cy) also appeared to have a short GF duration. Along with these cultivars, 2 other genotypes are worth remarking. The spring genotype Triumph (tr) had a low GF rate for a 2-row. In contrast, the North African genotype Tichedrett (TI) had a high GF rate for a 6-row. This characteristic may correspond to an adaptation to environments with a high risk of drought when the grain is filling.

Figure 2 shows that the relation between 1000 -grain weight and GF rate was not linear. We can see that for high rates of GF, the increase in 1000 -grain weight was smaller.

GF duration was not correlated with kernel weight, either in the 2-rows $\left(r=0.138^{n s}\right)$ or in the 6 -rows $\left(r=0.021^{\mathrm{ns}}\right)$. The phenotypic correlation between rate and duration of GF was negative, both in the 2-rows $\left(r=-0.712^{\star \star}\right)$ and the 6-rows $\left(r=-0.520^{\star \star}\right)$. As noted above, the genotype Tichedrett had very high GF rate and kernel weight in comparison to other 6-rows and the latter correlation became non-significant when this genotype was not taken into account $\left(-0.470^{\text {ns }}\right)$. Bruckner and Frohberg (1987) in spring wheat, Jones et al (1979) in rice (Oryza sativa L), Ho and Jui (1989) in spring barley and Gebeyehou et al (1982) in durum wheat (Triticum turgidum L) found that GF rate and duration were not significantly associated. On the contrary, Triboi and Ollier (1991) reported a negative correlation between these 2 variables in winter wheat. In fact, the correlation depends on the set of genotypes and also on the experimental conditions as suggested by the data in figure 2 . The 6 -rows had a low 1000 grain weight and GF rate. Under these conditions selection for a higher GF rate may result in a higher 1000 grain weight as GF rate and duration are not negatively correlated (disregarding Tichedrett). For the 2-row varieties which already have a high 1 000-grain weight and a high GF rate, a selection for a higher GF rate is likely to produce a limited response only because of the negative correlation with the GF duration.

\section{Comparison of SG and GR parameters}

Figure 3 represents the relationship between the growth rates of the shoot and the grain. In 5 cultivars the GF rate was higher than the $S G$ rate. Four of them were 6-rows, Ager (AG), Gerbel $(\mathrm{GE})$, Matador (MT) and Plaisant (PL), and the last was a 2-row, Igri (Ig). Except for Triumph 


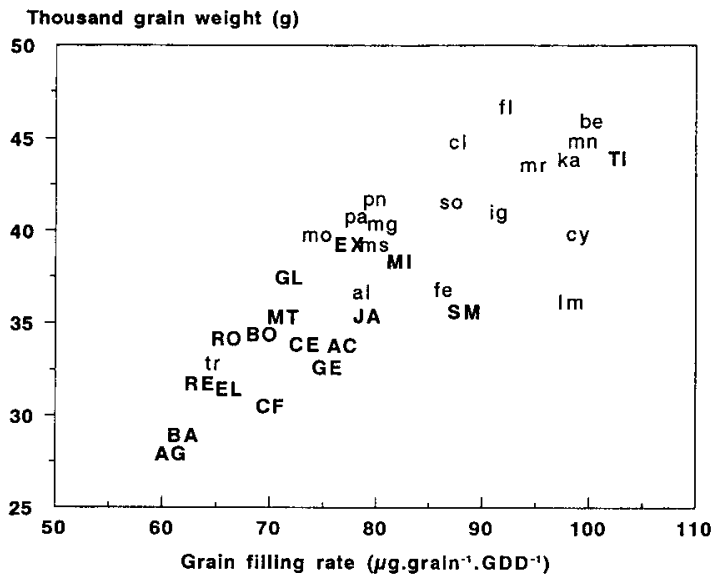

Fig 2. Relation between the final grain weight and the rate of grain filling of the 36 barley genotypes. The 6-rows are in upper case and in bold type. Varieties are coded according to table 1 .

(tr), the cultivars which had a SG rate $<1.40$ $\mathrm{g}^{\circ} \mathrm{m}^{-2} \cdot \mathrm{GDD}^{-1}$ or $50 \mu \mathrm{g} \bullet \mathrm{grain}^{-1} \bullet_{\mathrm{GDD}}-1$ had a higher GF rate. When all the 2-row varieties were considered, the average rates of $S G$ and GF were not significantly different (table II). On the contrary, the mean GF rate is slightly greater than the SG rate for the 6-row varieties. This implies that the higher yield of the 6-row cultivars is not due to a higher SG rate after anthesis but may be due to the retranslocation of a higher proportion of assimilates stored in vegetative parts before anthesis (Le Gouis, 1992).

Eight cultivars finished GF later than SG (fig 4). Five of them were 2-rows: Alpha (al), Clerix (cl), Flamenco (fl), Magie (mg), Marylin (mr); 3 were 6-rows: Celtic (CE), Express (EX), Robur $(\mathrm{RO})$. The other genotypes had similar GF and $S G$ ending times. For all the 2- or the 6-rows together, the filling of the grain ends after the growth of the shoot.

Based on our results, it is possible to distinguish 4 different phases during the GF period. These are slightly different from the phases described by Gallagher et al (1975) since ours are based on a linear approximation of grain and shoot growth. Figure 5 shows, for example, the kinetics of grain and shoot growth after anthesis of the 2-row cultivar Clerix (cl).

During the first phase, the growth rate of the shoot is greater than the filling rate of the grain. In wheat, Rawson and Evans (1971) suggested that cultivars setting more grains per spikelet had a longer initial lag between anthesis and the beginning of the linear grain growth. Sofield et al (1977), however, reported no consistent differ-

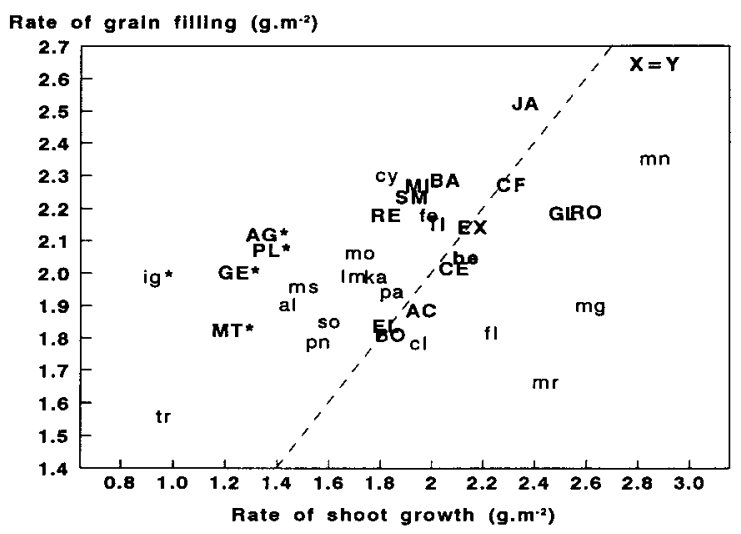

Fig 3. Relation between grain filling and shoot growth rates of the 36 barley cultivars. Varieties followed by an asterisk had a shoot growth rate significantly lower than their GF rate at the $5 \%$ level. The 6-rows are in upper case and in bold type. Var-ieties are coded according to table I.

ence between cultivars for the length of this period. We did not try to investigate the duration of the lag phase since its accurate estimation would prove difficult to carry out.

During the second phase, SG and GF were approximately equivalent for the majority of the cultivars. Photosynthesis adequately supplied the demand and no assimilate was stored in plant parts other than the grain or was translocated to the grain. A few varieties, however, showed a low growth rate of the shoot per kernel and had a lower SG than GF rate. Nevertheless, the 6row varieties as a whole seemed to rely more on pre-anthesis assimilation during this phase since their mean filling rate of the grain was higher than their mean growth rate of the shoot.

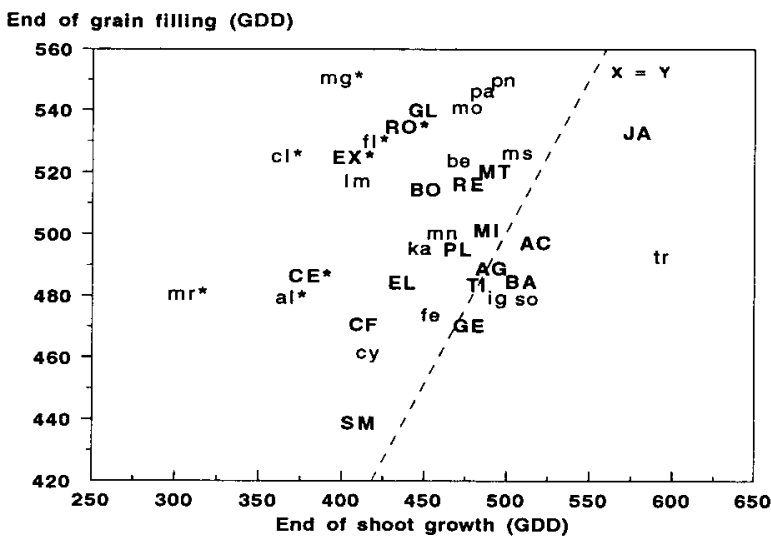

Fig 4. Relation between GF and shoot growth ends (growingdegree days) of the 36 barley cultivars. Varieties followed by an asterisk had a shoot growth ending time significantly earlier than that of grain filling at the 5\% level. The 6-rows are in upper case and in bold type. Varieties are coded according to table I. 


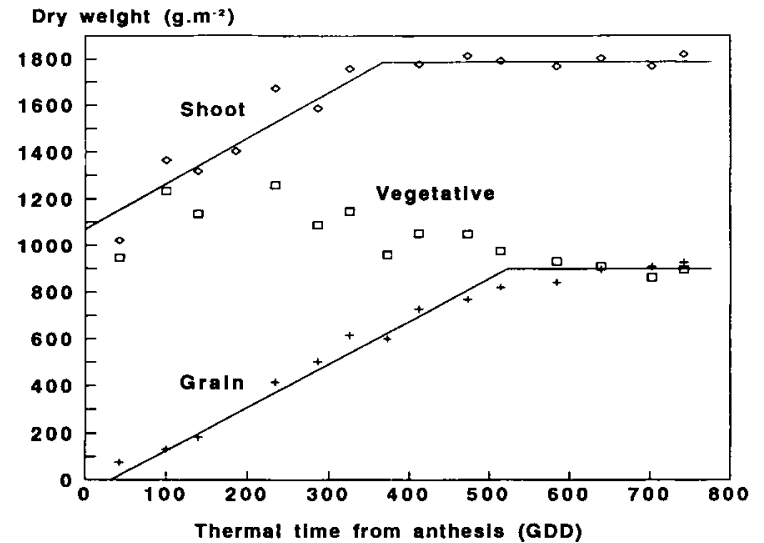

Fig 5. Shoot and grain growth of the 2-row winter barley cultivar Clerix after anthesis.

The average date at which the growth of the shoot stopped was before that at which the filling of the grain ended. There was therefore a phase during which the grain continued to fill while $S G$ was low or non-existent. However, most cultivars displayed no significant difference between the 2 dates (fig 4). This result may partly be due to the low discrimination power of the statistical test used.

During the fourth phase no growth occurred either in the grain or in the shoot.

Depending on the cultivar, the production of vegetative DM (DM of the shoot minus the grain) takes place differently. Changes in vegetative DM after anthesis of the cultivar Clerix is shown as an example in figure 5 . First there was an increase in vegetative $D M$ which terminated $\approx 100$ 200 GDD after anthesis. Such an increase, caused by the low accumulation of assimilates in the grain just after anthesis, has frequently been reported (eg Rawson and Evans, 1971; Gallagher et al, 1975). The dynamics then differ from one genotype to another. The vegetative DM of a genotype with similar rates and ends of GF and $S G$ remains approximately constant. A genotype with different rates and equivalent ends of GF and $S G$ has vegetative DM which decreases regularly. The vegetative DM of a cultivar with similar SG and GF rates but different SG and GF ends is constant to begin with and then decreases.

\section{CONCLUSION}

This study has shown the differences that existed in a set of winter barley genotypes for growth parameters of the grain and shoot. The use of a simple linear model has made it possible to compare shoot and grain growth. We have thus shown that some varieties may translocate assimilates from vegetative parts very early after anthesis. Additional studies still have to be carried out to investigate the effects of other environmental and genotypic sampling. This is particularly the case for the comparison between 2and 6-row genotypes. We have used linear regressions to describe grain and shoot growth. It would be of interest to look for non-linear models which could fit better to the data both for the grain and the shoot. Non-linear regression would make it possible to more accurately describe relations between grain and shoot growth.

\section{ACKNOWLEDGMENTS}

$I$ thank $M$ Leleu and $M$ Mériaux for their competent technical assistance and $L$ Jestin, $P$ Pluchard and $F$ Vear for their helpful comments on this paper.

\section{REFERENCES}

Bruckner PL, Frohberg RC (1987) Rate and duration of grain fill in spring wheat. Crop Sci 27, 451-455

Campbell CA, Cutforth HW, Selles F, DePauw RM, Clarke JM (1990) Dynamics of dry matter, $N$ and $P$ accumulation in the developing kernels of four spring wheat cultivars for irrigation and dryland. Can J Plant Sci 70, 1043-1056

Copeland PJ, Crookston RK (1985) Visible indicators of physiological maturity in barley. Crop Sci 25, 843-847

Dagnélie $P(1970)$ Les méthodes relatives à la régression. In: Théorie et Méthodes Statistiques. Les Presses agronomiques de Gembloux, Gembloux, vol II, 265-307

Daynard TB, Tanner JW, Duncan WG (1971) Duration of the grain filling period and its relation to grain yield in corn, Zea mays L. Crop Sci 11, 45-48

Gallagher JN, Biscoe PV, Scott RK (1975) Barley and its environment. V. Stability of grain weight. $J$ Appl Ecol 12, 319-336

Gebeyehou G, Knott DR, Baker RJ (1982) Rate and duration of grain filling in durum wheat cultivars. Crop Sci 22, 337-340

Ho KM, Jui PY (1989) Duration and rate of kernel filling in barley (Hordeum vulgare L). Cereal Res Commun 17, 69-76

Jones DB, Peterson ML, Geng S (1979) Association between grain filling rate and duration and yield components in rice. Crop Sci 19, 641-644

Le Gouis J (1992) A comparison between two- and six-row winter barley genotypes for above-ground 
dry matter production and distribution. agronomie 12, 163-171

Nass HG, Reiser B (1975) Grain filling period and grain yield relationships in spring wheat. Can $J$ Plant Sci 55, 673-678

Rawson HM, Evans LT (1971) The contribution of stem reserves to grain development in a range of wheat cultivars of different height. Aust $J$ Agric Res 22, 851-863

Riggs TJ, Gothard PG (1976) The development of barley grain: comparisons between cultivars for growth rate and $\alpha$-amylase activity. J Agric Sci (Camb) 86, 603-608

Scott WR, Appleyard M, Fellowes G, Kirby EJM (1983) Effect of genotype and position in the ear on carpel and grain growth and mature grain weight of spring barley. J Agric Sci (Camb) 100, 383-391

Sofield I, Evans LT, Cook MG, Wardlaw IF (1977) Factors influencing the rate and duration of grain filling in wheat. Aust J Plant Physiol 4, 785-797
Spiertz JHJ (1977) The influence of temperature and light intensity on grain growth in relation to the carbohydrate and nitrogen economy of the wheat plant. Neth J Agric Sci 25, 182-197

Triboi E (1990) Modèle d'élaboration du poids du grain chez le blé tendre (Triticum aestivum Thell). agronomie 10, 191-200

Triboi E, Blanchon J, Magne J (1985) Déterminisme du poids moyen du grain chez le blé. Effet sur la variation du rendement. CR Acad Agric Fr 71, 871886

Triboi E, Ollier JL (1991) Evolution et rôle des réserves glucidiques et azotées des tiges chez 21 génotypes de blé. agronomie 11, 239-246

Van Sanford DA (1985) Variation in kernel growth characters among soft red winter wheats. Crop Sci $25,626-630$

Wych RD, McGraw RL, Stuthman DD (1982) Genotype $x$ year interaction for length and rate of grain filling in oats. Crop Sci 22, 1025-1028 